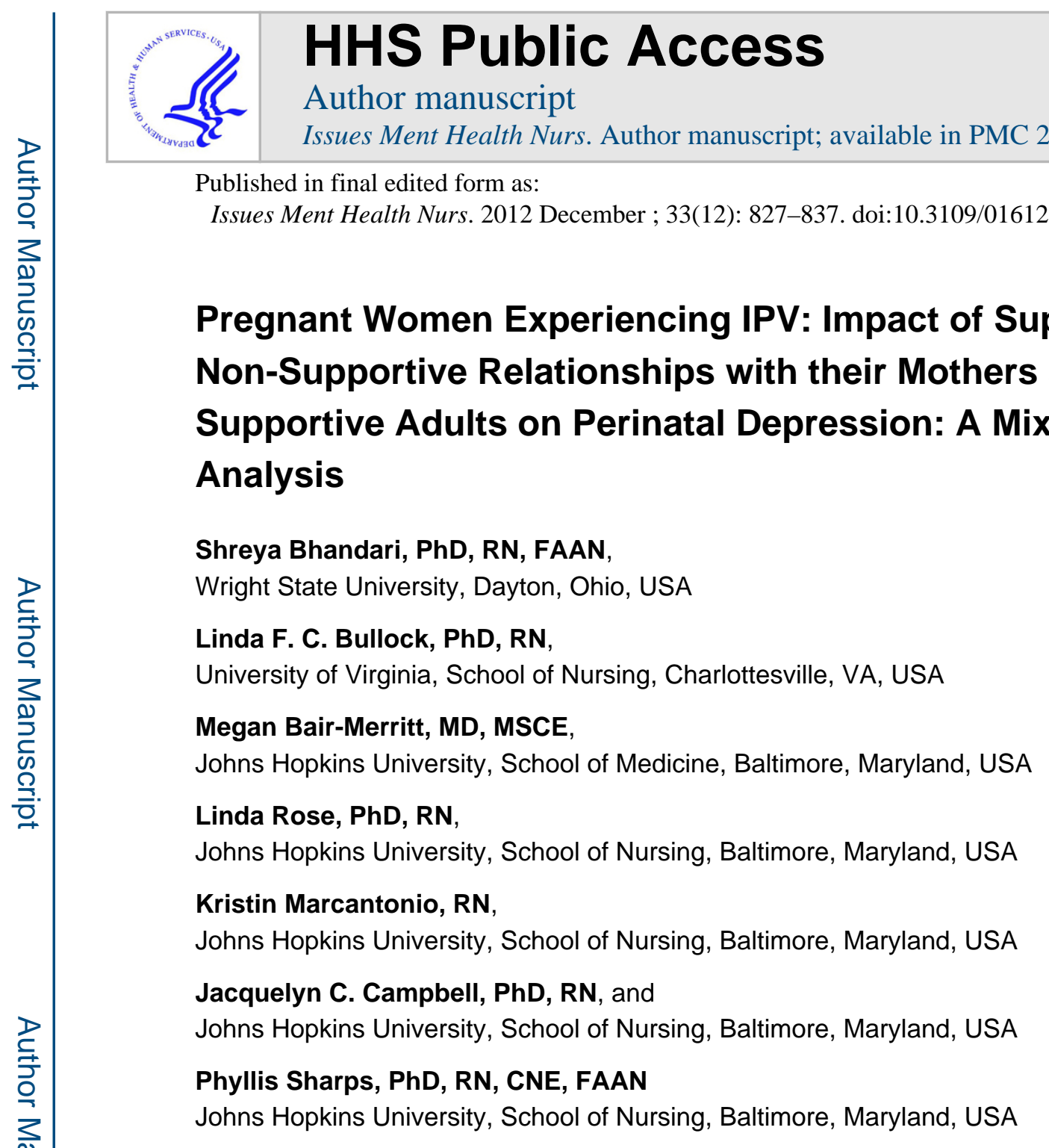

\begin{abstract}
The current study explored the views of women experiencing interpersonal violence (IPV) and their relationship with their mothers or other supportive adult, and determines how this relationship affected perinatal depressive symptoms. The sample consisted of 30 urban and rural pregnant women enrolled in a larger ongoing randomized controlled trial. Data from quantitative instruments that measured depressive symptoms were examined in combination with qualitative interview data collected at baseline and six months post-natal. Women describing positive relationships with their mothers or another supportive adult reported statistically significant lower depressive symptoms scores $(p<.05)$.
\end{abstract}

For women who experience intimate partner violence (IPV) before, during, and after pregnancy, the risk of perinatal depression escalates with rates as high as $47.6 \%$ (Golding, 1999; Rodriguez et al., 2010). IPV during pregnancy has been associated with significant

Address correspondence to Shreya Bhandari, Wright State University, Department of Social Work, 271 Millett Hall, 3640 Glenn Hwy, Dayton, OH 45435. shreya.bhandari@wright.edu.

Declaration of interest: The authors report no conflicts of interest. The authors alone are responsible for the content and writing of the paper. 
risk for post-partum depression. Perinatal depression during or after pregnancy can seriously affect women's abilities to problem-solve and to make decisions about the abusive relationship and parenting (Wilen \& Mounds, 2006).

One factor that has been shown to improve pregnant women's mental health is social support (Jones, Bogat, Davidson, Eye, \& Levendosky, 2005). Studies have suggested that, among women facing IPV, positive social support during pregnancy results in higher selfesteem and less anxiety (Levendosky et al., 2004). Women experiencing IPV who receive support from a network of supportive family, friends, and/or non-abusive partners may also have lower rates of depression. For abused women, the lack of positive support from partners often increases stress and anxiety and has adverse effects on mental health (Coker et al., 2002).

The purpose of this study was to explore pregnant abused women's views about their relationship with their mothers and other supportive adults, as a potential source of support and to examine how this relationship impacted perinatal depression. The study sample was drawn from an ongoing multi-site, randomized controlled intervention trial designed to reduce IPV during and following the child-bearing year.

\section{BACKGROUND AND REVIEW OF THE LITERATURE}

The Centers for Disease Control and Prevention define intimate partner violence (IPV) as the forceful control of one intimate partner by the other that includes threats or acts of physical, emotional, or sexual violence. Intimate partners include present or past partners, spouses, and boyfriends or girlfriends, both in heterosexual as well as same sex couples (Saltzman, Fanslow, McMahon, \& Shelley, 1999). IPV during pregnancy includes rape, physical assault, emotional abuse, and stalking perpetrated by a current or former date, boyfriend, husband, or cohabiting partner (Tjaden \& Thoennes, 2000, p. 16). The prevalence of IPV during pregnancy ranges from $0.9 \%$ to $20 \%$, with $4-8 \%$ being the most common range in the United States (Campbell, Garcia-Moreno, \& Sharps, 2004; Martin, Mackie, Kupper, Buescher, \& Moracco, 2001; Saltzman, Johnson, Gilbert \& Goodwin, 2003; Sharps, Laughon, Giangrande, 2007). An increase in physical, emotional, and social needs during pregnancy make it a particularly vulnerable period to experience IPV (Noel \& Yam, 1992).

Research is inconclusive about whether pregnancy increases the risk of abuse. Although some researchers conclude that pregnancy is a time of increased risk for women (Webster Chandler, \& Battistutta, 1996), others indicate no difference in risk (Jasinski \& Kaufman, 2001) or they state that for some women pregnancy is a time of relief from abuse (Campbell, 1998). But little is known about what factors contribute to the different patterns of IPV against pregnant women or why pregnancy appears to be a respite period for some and a period of increased danger for others (Taillieu \& Brownridge, 2010). IPV prior to pregnancy increases a woman's risk of additional abuse pre- and post-natal by $10.4 \%$ to $24.4 \%$ (Amaro, Fried, Cabral, \& Zuckerman, 1990; Martin, et al., 2001; Parker, McFarlane, \& Soeken, 1994). Furthermore, pregnant women who leave an abusive relationship are at a higher risk for homicide than non-pregnant women (Decker, Martin, \& Moracco, 2004; Horon \& Cheng, 2001; Parsons \& Harper, 1999). 
Abuse during pregnancy is related to several serious and potentially life threatening outcomes for both mother and fetus, including, but not limited to preterm labor, low maternal weight, vaginal bleeding, miscarriage, fetal injury, rupture of the uterus, low birthweight, kidney infection, ante partum hemorrhage, caesarean delivery, preterm labor or delivery, sexually transmitted infections, and fetal or maternal death (Fried, Cabral, Amaro, \& Aschengrau, 2008; Martin et al., 2001; Saltzman et al., 2003; Yost, Bloom, McIntire, \& Leveno, 2005). Pregnant women may cope with the stress of abuse by smoking or using other substances (Martin et al., 2001). Another major detrimental mental health outcome among pregnant women experiencing IPV is reported high levels of depressive symptoms, about 2.5 times more than non-abused pregnant women (Dunn \& Oaths, 2004; Martin et al., 2006).

\section{Perinatal Depression}

The prevalence of perinatal depressive symptoms, which encompasses major and minor depressive episodes, occurring either during pregnancy or within the first 12 months following delivery ranges from $10 \%$ to $51 \%$ (Bennett, Einarson, Taddio, Koren, \& Einarson, 2004; Gaynes et al., 2005; McKee, Cunningham, Jankowski, \& Zayas, 2001; Stampfel, Chapman, \& Alvarez, 2010). Anxiety, life stress, prior depression, lack of social support, unintended pregnancy, relationship factors, and public insurance are all risk factors for perinatal depressive symptoms (Lancaster, Gold, Flynn, Yoo, Marcus, \& Davis, 2010).

An analysis by the Centers for Disease Control and Prevention (CDC) Pregnancy Risk Assessment Monitoring System (PRAMS) of 14,609 records of women who had recently delivered in Colorado, New York, or North Carolina found that the self-reports of depression were associated with experiencing partner-associated stress (O.R. $=1.9,95 \% \mathrm{CI}$ $=1.5,2.5)$ and physical abuse during pregnancy $(\mathrm{O} . \mathrm{R} .=1.6,95 \% \mathrm{CI}=1.1,2,4)(\mathrm{Gross}$, Wells, Radigan-Garcia, \& Dietz, 2002). Additionally recent studies confirm that IPV increases the risk of perinatal depression (Beydoun, Al-Sahab, Beydoun, \& Tamim, 2010; Brett, Barfield, \& Williams, 2008; Campbell, Garcia-Moreno, \& Sharps, 2004). Support from another close family member, particularly a woman's mother, may be important in buffering the stress of pregnancy and in protecting her from depression.

\section{Mother-Daughter Relationships}

Feminist researchers (Chodorow, 1989; Gilligan, Rogers, \& Tolman, 1991; Soenens, Vansteenkiste, Luyckx, \& Goosens, 2006) maintain that girls who are attached to their mothers remain so even during their adolescent years, and this relationship is stronger than that with their fathers (Larson \& Richards, 1994). Other research suggests that a mother's insecure attachment, with negative feelings towards her daughter, is connected to her daughter's depressive symptoms. A mother's insecure attachment with her son can lead to his use of violence and aggression to gain power and control as he grows older (McClellan $\&$ Killeen, 2000). To prevent the transmission of depression or aggression to the next generation, it is important that girls and young adult females have a positive relationship with a parental figure, particularly mothers, with the subsequent influence of that relationship promoting a pregnant woman's mental health, overall well-being, and the health of her baby. 


\section{Depression and Social Support in the Context of IPV}

Coker and colleagues (2002) show that with regard to disclosing IPV, it is not just enough to have someone with whom to talk. To create a positive impact on mental health, they emphasize the importance of having someone who is emotionally supportive to talk to. IPV isolates women from personal or social relationships and creates a reduced sense of worth or self-esteem, both of which are mutually reinforcing. Social support may mitigate both of these characteristics by enhancing psychological well-being and also improving coping skills, thereby helping the woman build alternatives to the current abusive relationship. After controlling for frequency of IPV, abused women with higher levels of social support are significantly more likely to report current better mental and physical health—specifically reduced symptoms of anxiety, depression, PTSD, and suicide ideation - than abused women reporting lower social support (Coker et al., 2002).

\section{METHODS}

\section{Participants and Setting}

The current study used data collected as a part of the Domestic Violence Enhanced Home Visitation (DOVE) study, a multi-site randomized controlled trial of an intervention to decrease IPV in pregnant women. The five-year DOVE study, which began in 2006, is ongoing and has enrolled 239 women from an Eastern metropolitan area, and a Midwestern rural area, both in the United States. The larger randomized control trial, and this mixed methods study also, included participants who met the following criteria: (1) $\leq 31$ weeks pregnant; (2) reported IPV within the last 12 months as disclosed to a research nurse or home visitor on the Abuse Assessment Scale (AAS; Parker \& McFarlane, 1991) and/or the Women's Experience in Battering (WEB) scale (Coker, Smith, McKeown, \& King, 2000); (3) English speaking; and (4) enrolled in a prenatal home visiting program of a participating health department. Referrals for the study were received from the respective rural and urban health departments. Since the current mixed study was a subset of the larger randomized control trial, it was restricted to the eligibility criteria set by the larger study.

For the qualitative component of the study, women were selected from the larger sample of women enrolled in the DOVE clinical trial. After informed consent was obtained for participation in the trial, women were asked if they were interested in participating in a series of qualitative interviews. From those who expressed interest, a subset of women was selected, using a theoretical sampling procedure, based upon characteristics of theoretical interest and with a goal of addressing gaps in the literature. For example, racial background, age, and history of previous abuse were considered. Theoretical sampling does not have an objective of representing a population or increasing the generalizability of results. Instead, the focus is on potential insights from the voices of the population studied, and of increasing depth of the focus areas (Charmaz, 2006).

With the recruitment at the rural sites progressing faster than the urban site, 30 women, 21 from the rural site and 9 from the urban site, completed qualitative interviews conducted during pregnancy and at three- and six-months postnatal. This sample of 30 women was considered sufficient for the current analysis because saturation was reached, in that 
gathering new data did not afford any new theoretical insights (Charmaz, 2006). The study was approved by the Institutional Review Boards at the participating agencies.

\section{Data Collection for the DOVE Randomized Trial}

Recruitment for DOVE study began in 2006. For the clinical trial, both quantitative and qualitative data were collected by trained research staff at a safe and private location of the participant's choice. Quantitative data were collected at baseline (31 weeks pregnant or less), delivery, and 3-, 6-, 12-, 18- and 24-months postnatal from all women participating in the study. Qualitative interviews were conducted with the subset of 30 women at baseline, 3months, and 6-months postnatal. Qualitative interviews also were conducted at 12-months and 24-months postnatal. Findings reported here are from qualitative interviews and selected quantitative data collected at baseline and 6-months postnatal. The clinical trial is currently ongoing and data for time points past six months are still being collected and analysis is continuing. Only the analysis of the baseline data and the six-month data were available for this report.

The qualitative portion of the study, consisting of semi-structured in-depth interviews with a subset of women in both the treatment and control groups, was designed to enhance the interpretation of the quantitative data related to the impact of the intervention, in that unique aspects related to patterns of IPV/pregnancy/parenting experiences were explored. This also allowed us a method of triangulation to confirm the findings (Creswell \& Plano-Clark, 2007). Ethical concerns related to the safety of the women participating in the interviews were addressed. Women were asked if it was safe to do a home visit; if not, the nurse ascertained the safety issue and made appropriate referrals for the women. During the home visit, the women were asked about current safety. All study personnel were trained in safety procedures. Qualitative interviews were conducted in the participants' homes unless they preferred an alternate location.

Topical areas in the interview were: descriptions of family and current living situation; experiences of pregnancy in the context of IPV; family context of abuse, including children; response to abuse and sources of support; resources and barriers in the setting (urban versus rural); and strategies for coping with the abuse. Women were encouraged to talk about the experience of abuse over time, and to discern any perceptions of patterns (for example, events occurring before and after an abusive episode; timing of the abuse related to pregnancy and childbirth landmarks).

Interview questions were open-ended and broad (e.g., "Other women have reported abuse by their partner while pregnant. Is this something that has ever happened to you? What was that like for you?"). All interviews at baseline, 3-, 6-months postnatal, and later asked similar questions, but the follow-up interviews emphasized the changes in the women's experiences and perceptions from the baseline interview. Follow-up probes were used to elicit descriptions of contextual factors (i.e., what was happening at the time). Interviews lasted from 30 to 60 minutes (average: 45 minutes) and were conducted in the participants' homes. Questions were not necessarily asked in the same order with each woman, since the goal was to ensure that the women told their individual stories according to what was important to them. All topical areas outlined in the interview guide were covered with each woman. 
Interviewing techniques were used to ensure that the women's descriptions were understood, for example, clarification of terms or phrases (e.g., clarifying, "We were fussing," which was used by several women to describe argumentative interactions with their partners) to avoid assuming shared meaning.

This article reports only the qualitative findings related to the women's descriptions of relationships with their mothers, the experiences of support from their mothers, and other sources of support. Analysis of the full qualitative data set is ongoing and will be reported elsewhere. All topical areas of the interviews, noted above, were examined for evidence of the women's experiences of social support in close relationships.

\section{QUANTITATIVE INSTRUMENTS}

\section{Depressive Symptoms}

The Edinburgh Depression Scale (EPDS) is a 10-item scale that identifies women at risk for perinatal depression (Cox, Chapman, Murray, \& Jones, 1996). Responses are scored from 0 to 3 according to increasing severity of the symptoms, with four items reverse scored and the total score summed. For the purpose of this study, a woman with a score of 13 or more was considered to have depressive symptoms associated with depression (Matthey, Henshaw, Elliott, \& Barnett, 2006).

\section{Data Management and Analysis}

The first phase of data analysis involved examining the qualitative data from the interviews at baseline up to 6-months postnatal, which afforded insights into women's relationships with their mothers that could be categorized into positive or negative relationships. The second phase consisted of examining the quantitative scores of depressive symptoms with the qualitative data based on the relationship with their mothers. Two $t$-tests were conducted. First, a $t$-test was used to compare mean depressive symptom scores of women with positive and negative relationships with their mothers. Second, within the group of women who had negative relationships with their mothers, we compared mean depression scores of women who had other sources of support and women who did not have other sources of support. Finally, the results of the two data sources were integrated into an overall interpretation of women's relationships with their mothers or other supportive adult.

\section{QUALITATIVE ANALYSIS}

Interviews were transcribed iteratively and audio files were compared with written transcripts for accuracy. The qualitative data were analyzed using the software NVIVO-8. Data were examined for processes and pivotal points in the women's experiences (Strauss \& Corbin, 1998). The analysis began with an open coding of the data-an initial reading of the transcripts where codes, that were deemed to be of potential relevance to the problem being studied, were identified (Glaser, 1978). These codes emerged directly from the data and frequently the words of the participants themselves were used as code "labels." The next stage of collapsing the codes and creating broader, more abstract, categories was carried out by the larger research team, consisting of six to eight members, including the research nurse data collectors and researchers with expertise in IPV and qualitative research methods. This 
research team met regularly to reach consensus on the major categories and to collapse the 37 codes into the final 12 categories (see Table 1).

To address the research question of pregnant abused women's views about their relationship with their mothers, and how this maternal support (or lack thereof) impacted depression in experiencing IPV, codes pertaining to portions of the interviews addressing women's support in dealing with the abuse were considered. Examples of questions included in the interview that dealt with family support were: "How comfortable are you in asking for help from family members when abused?" and "Who do you ask for help and support?" Codes for answers to these questions included "issues with mom affecting relationship," "family issues," "informal support," and "family and friends help for domestic violence." The objective of the larger randomized control trial was to evaluate the DOVE intervention rather than to explore participants' relationship with their mothers or supportive adults. Even though participants' relationships with their mothers were not explicit questions in the interview, all the participants shared information about this relationship in response to the above questions and spontaneously at other points of the interview; hence we decided to explore it further by combining it with quantitative data as this facet has not been fully explored by prior researchers.

\section{RESULTS}

Demographics of the subsample included in this analysis are shown in Table 2. Roughly half were African American $(n=13)$, half were Caucasian $(n=15)$ and two of the women were American Indian $(n=2)$. Participants were relatively young, with a mean age of 23.6 years (range: 16-34 years). The women in the subsample were predominantly from low-income households.

Based on data from the qualitative interviews, the 30 women were classified as having negative relationships with their mothers if they described the relationship as strained, interfering, or problematic. Women were classified as having a positive relationship with their mothers if they shared that their mothers offered them unconditional support, were very close to them, or that the participant could "share everything with them."

\section{Positive Relationships with Mothers}

Eleven women were classified as having a positive relationship with their mother. These women talked about their mothers as being ready to lend a hand in all aspects of their life, including decisions about children and dealing with abuse. For example, a 20-year-old urban woman, who contemplated putting her baby up for adoption, described the support offered by her mother for the new baby: "My mother says 'I'm gonna be here to help you, be here to support you, you don't have to worry about nothing.' ",

Women in this group reported various types of support from their mothers in dealing with their abusive partners, whether it was actually intervening in the situation or helping the participant stand by her decisions. Most of the participants explicitly identified their mothers as their preferred source of support and their most supportive family member. A 16-year-old rural teenager was asked if she sought help from anyone for her abuse and described, "My 
mom has tried to get me help like, she used to talk to one of the police officers that always goes in where she worked." She went on to say, "I'm only comfortable asking my mom for help." Another young woman, an 18-year-old who had a strong bond with her mother and grandmother, said that she knew she could talk about anything with them and was certain that they would give her advice on handling abuse in her life:

All my life, she's [mom] the only person I really want to live with. I don't want to leave my mom ... I love being with my mom because she is not like a parent, she is like my friend.... I am really confident in talking to them [mom and grandmother] about anything ... because they will tell me what I should do, and give me advice on how to handle the situation [abuse].

Thus, even though mothers did not always agree with or approve of the relationships with their partners, they provided unconditional support by respecting their daughters' decisions and standing by their daughters.

\section{Negative Relationships with Mothers}

Nineteen women were classified as having a negative relationship with their mother. Many of their stories involved longstanding conflict with mothers and family histories of abuse and neglect. A 20-year-old urban woman stated, "And just far as with my mother, me and her never really had a regular mother-daughter relationship." Another rural woman, age 24, described her mother's history of substance abuse as the reason for the strain in their relationship for all these years: "My mom used to be on drugs really bad ... So that's where most of me and her anger come from because I didn't approve of what she was doing."

Other women described being taken away by child protective services, having little or no contact with their biological mother during childhood, or spending a portion of their childhood in abusive foster and adoptive parents' homes. One 22-year-old rural woman, abused by both her biological and adoptive mothers said:

I had a really hard life, too. I had two mothers [biological and adoptive mothers] reject me ... She's [biological] not a mom. She's definitely not a mother. She is more of a girlfriend type person. She's very irresponsible. She's never grown up.... You know, she just, she sent me pictures from my childhood ... But you don't see the pictures where she let guys beat me up or where a guy smashed my head into a table and she [biological mother] didn't take me to the doctors.

For some women, their mothers were seen as not supportive about the personal choices they made in their lives, such as teenage pregnancy, and this resulted in strain in their relationship. For others, fights and misunderstandings with their mothers about dating, money, or child care, led to feeling controlled and brought about a strain in the relationship. Some mothers blamed the daughters for everything going wrong in their lives. As one woman described it: "I'm not going to sit up here and paint a pretty picture because we have a very bad relationship and it has been that way with me and her since I've been little." 


\section{Negative Relationship with Mother; Positive Relationship with Another Supportive Adult}

We further examined the interviews of the women who were first classified as having a negative relationship with their mother. We were interested in determining if they had developed alternative sources of support, in ways that might also impact their emotional health. Twelve women were classified in this way. For example, a 32-year-old rural woman had a negative relationship with her mother but a strong relationship with her grandmother:

Well, my grandmother has taken care of us since we were little ... you know, she's kind of like mom to us because my parents were strung out on crack and all kind of things like that, and so she's always been like the supportive one in the family.

Similarly, a 20-year-old urban woman shared her lack of familial support ("I don't really have no family. I just don't really like my family."), but identified her grandfather as "the only one that's really there for me."

As these excerpts illustrate, some women were able to reach out to an alternative "supportive" figure within their families as a source of support for them. Others identified supportive adults outside the family. For example, a rural woman, who regularly visited a therapist and who had a strained relationship with her mother, said, "I would say going to therapy, and then making friends at work also helped ... but talking to them while we're there at work helps."

\section{Negative Relationships with Mother; No Supportive Relationship with Another Adult}

Seven women were classified this way. These women told stories of being alone, and of being expected to manage on their own. For example, a 20 -year-old urban woman, whose depression did not improve from baseline to six months later, described her mother as absent when she was a child, but now trying to control her adult life, "the way that she should have been when I was younger, that's the way she [mother] is acting now ... but when I was 13, I didn't have to tell her anything. I could go wherever I want to, and never had to call her." This participant expressed anger at her mother for not being a "mother" when she needed her the most (during her adolescence) and for the negative impact it had on her current relationship with her mother.

Similarly, a 22-year-old woman whose depression did not improve at six months postnatal, and whose mother was deemed unavailable for her during her teenage years, shared that she did not have any other support and was expected to parent her little siblings:

I've been on my own since I was 16, and I've taken care of my sisters that whole time ... Yeah. Yeah. I mean, we lived, when we lived with my mom and dad [but] we had to take care of ourselves.

\section{Integration of Qualitative and Quantitative Results}

The classification of women into mutually exclusive groups based on their available support from mothers or other adults was done based on the analysis of the qualitative data. As these qualitative data were examined for each subset of women in conjunction with their quantitative data, it seemed that there were differences in women's mental health over time between those who had support from mothers and those who did not have this support. At 
six months postnatal, it appeared that the women who had negative relationship with mothers had depression scores that were higher, overall, than those of the women with positive relationships with mothers. To clarify and validate this finding, the quantitative measures of depressive symptoms were statistically analyzed for significant differences between TABLE 5 Six Month Depressive Symptom Scores of DOVE Participants with Negative Relationship with their Mothers Depressive Symptoms Scores Negative Relationship with Mother, Positive with Another Adult $(n=12)$ Negative Relationship with Mothers, no Other Support ( $n=7$ ) Mean 618 Range 0-11 13-28 these two groups. Mean scores on the Edinburgh Depression Scale (EPDS) were analyzed using the $t$-test for independent samples.

Results of Quantitative Analysis-Differences in depressive symptoms (EPDS) scores between the two groups were non-significant at baseline (Table 3). However, at 6-months postnatal, women classified as having a negative relationship with their mothers $(n=19)$ were significantly more depressed than women who had a positive relationship with their mothers $(n=11)(t(28)=2.15, p<.05)($ Table 4$)$.

In order to answer the question of whether an alternative source of support would have a similar positive relationship to women's mental health, we re-examined the EPDS scores of the women with negative relationships with mothers, comparing those who had alternative sources of support to those who did not. In order to conduct this analysis, the 19 women with a negative relationship with their mother were further divided into "negative relationship with mothers, but positive with another adult" $(n=12)$ and "negative relationship with mothers and no other adult support" $(n=7)$ (Table 5). An independent $t$ test of mean scores on the EPDS scores showed a highly significant difference in the depressive symptom scores at 6-months postnatal between the two groups. As shown in Table 6, at 6-months postnatal, women with a negative relationship with their mother and no other supportive adult in their lives had significantly higher depression scores than women with a negative relationship with their mother, but a positive relationship with another adult $(t(17)=5.71, p<0.0001)$.

\section{DISCUSSION}

In this study, the perinatal depressive symptom scores of women with negative relationship with their mothers were significantly higher than women with positive relationships at 6months postnatal. The results of this mixed methods analysis support the conclusion that a positive and supportive mother-daughter relationship is important in promoting emotional well-being for new mothers, especially when the pregnant daughter is experiencing IPV. Evidence documents that poor maternal mental health has a strong influence on parenting (Lyons-Ruth, Wolfe, Lyubchik, \& Steingard, 2002). Though the data do not establish a causal relationship between the quality of maternal relationship and mental well-being, women in our sample who had a positive relationship with their mothers $(n=11)$ had significantly lower depressive symptom scores at 6-months postnatal. Perhaps even more importantly, our results indicate that when the women had a positive relationship with either their mother or another adult, the women's depressive symptoms scores were significantly lower. This suggests that while the women seemed to benefit from a positive relationship 
with their mother, that a relationship with another supportive adult can be equally effective. Of concern however, was that seven women who reported the highest depression scores had the poorest relationships with their mothers and had no other adult social support.

The women in this study seemed to be aware of the value and importance of positive family relationships. For the women who described a troubled relationship with their mother that spanned a life time, they portrayed a stance of being "independent," and "taking care of self." However, these same women reported levels of depression that were of concern and their qualitative interviews portrayed an attitude of resignation. It should be noted that not all of these women reported an absence of involvement with their mothers. Rather, there were several women who were involved in ongoing relationships with their mothers, but concluded the mothers' behaviors were not supportive and in some cases, actually destructive. It may be that the mothers themselves felt they were offering support, but it was construed by the women as a source of increased stress.

While we set out to examine the nature of mother-daughter relationships among abused pregnant women, our findings from the qualitative data provided evidence of the influence of "other" supportive adult on perinatal depressive symptoms. It should be noted here that women in both groups ("mother support," "no mother support") had similar depression scores at baseline, but only the women who had a positive relationship with either their mother $(n=12)$ or another "supportive" adult $(n=11)$ showed significant improvements six months later. It could be that the effect of IPV at baseline was similar for all women, but as the pregnancy progressed, the women with the support (regardless of the source) were able to make the changes that they wanted to make, and also were able to feel more positive about themselves as parents. This finding is consistent with other studies that have shown that abused women who receive support from friends, family, or caring adults are less likely to experience depressive symptoms. Social support has been found to reduce by $50 \%$ the risk of adverse mental health outcomes, including depressive symptoms, among abused women (Coker et al., 2002). Previous studies also have shown that a supportive relationship with another adult plays an important role in helping a pregnant woman to form a strong bond with her unborn child (Alhusen, 2008; McClellan \& Killeen, 2000). In fact, Bowlby (1988), who defined the construct of attachment, advocates that one of the best prevention strategies for insecure attachments is contact with other supportive adults. In another social support intervention study, pregnant women who received social support experienced better emotional well-being, had higher birthweight babies, fewer very low-birthweight babies, greater frequency of spontaneous onset of labor and vaginal delivery, and decreased use of epidural anesthesia compared to the control group (Oakley, Rajan, \& Grant, 1990).

\section{Clinical Implications}

Providers seeking to improve pregnancy and parenting outcomes need to screen for depression and examine the childhood and familial experiences of pregnant and postnatal women. This assessment should include the woman's history of her relationship with her mother and the support she received during her younger years, as well as the support she is receiving currently. Abused women with no supportive adult in their life may have dual obstacles to effective parenting: high depressive symptoms and low self-esteem. The stories 
of the women in this study illustrate the lasting impact of their negative childhood experiences with their mother on their life experiences as adults. Many vividly recalled, and often with anger, the lack of a positive mother "figure" in their life. Of greatest concern in this study were the seven women who were in the "negative relationship with mother/no other supportive adult" group.

The persistent depression for a small number of women with no identifiable source of support is of great concern in regards to these women and to their children and their children's care. These women had depressive symptom scores that were high at baseline and remained high six months later. For these women, this lack of a positive and supportive relationship with their mother may challenge their abilities to effectively parent their own children. It may be that without behaviors learned from their own childhood related to promoting positive infant growth and development, and without an example of what constitutes a loving relationship with another adult, these mothers will be doubly challenged in their parenting role. The results of this study further support a clinical approach that includes an assessment of abused or depressed pregnant women's relationship with their mother, or other informal sources of support, to determine the presence of positive adult role-model mentoring for these women. Interventions might include connecting them with resources to enhance supportive adult relationships. These interventions should be developed and tested to determine if the support mediates the depression that might occur as a result of social isolation.

\section{Strengths and Limitations of the Study}

The strengths of the study are the use of prospective data to avoid recall bias and the use of a mixed method research design. The qualitative findings help increase our understanding of why some women may have higher depressive symptom scores than others during pregnancy and early postpartum. Attachment theory helps to interpret the findings and offers possible solutions to the problem of generational insecure attachments. Providing supportive mentors for girls and young women whose bonds with their own mothers are not strong may improve their own psychosocial status and their parenting.

The generalizability of the findings is limited by the convenience non-representative (although demographically diverse) sample. The small sample size for this analysis, while appropriate for the qualitative data, was a limitation for the quantitative analysis. Though most qualitative data give ample evidence through several instances to be able to classify positive and negative relationships, we acknowledge the limitation of a recent negative interaction coloring the participant's description of the mother more negatively and hence being classified as a negative relationship. Further research with larger samples is needed to examine the impact that an abused pregnant woman's relationship with her mother has on her mental well-being as well as her parenting and attachment skills in the context of the IPV. Our research team will investigate these questions in a future analysis with the larger sample at the completion of the clinical trial in order to address the issue of generalizability of the findings to a larger population.

Of note, a recent study of postnatal depression and social support with a larger $(n=410)$ sample of new mothers showed that the majority of the participants identified their mothers 
as their primary source of support, and that the participants who had functional support from their families were less likely to be depressed at 6-weeks postnatal (Leahy-Warren, McCarthy, \& Corcoran, 2011). IPV was not included in this study and only first-time mothers were studied. The authors identified the important roles of the specific dimensions of functional support—including informational, instrumental, emotional, and appraisal - that participants' mothers provided. The findings of this study and the study we have reported here, support the recommendation that family support—both sources and types—be assessed for pregnant women as a way of enhancing their mental health. Future analyses of the data from this study will consider the mechanisms by which maternal support influences an abused pregnant women's mental health. Interventions can then be identified and tested.

Despite these limitations, the findings of the study provide important new directions for further research in the area of IPV, depression, and the role of supportive figures. Even with a limited sample of 30 women, we detected statistically significant results. Hence these findings should be tested with a larger sample to see if the apparent differences in depression hold. Additional qualitative studies are needed to examine the women's perceptions of how the quality of the relationship with one's mother or another supportive adult is important to their emotional health as they deal with IPV during pregnancy and in the immediate postpartum period.

\section{REFERENCES}

Alhusen JL. A literature update on maternal-fetal attachment. Journal of Obstetric and Gynecologic \& Neonatal Nursing. 2008; 37:315-328.

Amaro H, Fried LE, Cabral H, Zuckerman B. Violence during pregnancy and substance abuse. American Journal of Public Health. 1990; 80:575-579. [PubMed: 2327535]

Bennett HA, Einarson A, Taddio A, Koren G, Einarson TR. Prevalence of depression during pregnancy: Systematic review. Obstetrics and Gynecology. 2004; 103:698-709. [PubMed: 15051562]

Beydoun H, Al-Sahab B, Beydoun M, Tamim H. Intimate partner violence as a risk factor for postpartum depression among Canadian women in the Maternity Experience Survey. Annals of Epidemiology. 2010; 20(8):575-583. [PubMed: 20609336]

Bowlby, J. A secure base: Parent-child attachment and healthy human development. New York, NY: Basic; 1988.

Brett K, Barfield W, Williams C. Prevalence of self-reported post-partum depressive symptoms-17 states, 2004-2005. Morbidity and Mortality Weekly Report. 2008; 57(14):361-366. [PubMed: 18401329]

Campbell J. Abuse during pregnancy: Progress, policy, and potential. American Journal of Public Health. 1998; 88:185-187. [PubMed: 9491004]

Campbell J, García-Moreno C, Sharps P. Abuse during pregnancy in industrialized and developing countries. Violence against Women. 2004; 10(7):770-789.

Charmaz, K. Theoretical sampling, saturation, sorting. In: Charmaz, K., editor. Constructing grounded theory: A practical guide through qualitative analysis. Thousand Oaks, CA: Sage; 2006. p. 96-122. (p. 96)

Chodorow, NJ., editor. Feminism and psychoanalytic theory. New Haven, CT and London, England: Yale University Press; 1989.

Coker AL, Davis K, Arias I, Desai S, Sanderson M, Brandt H. Physical and mental health effects of intimate partner violence for men and women. American Journal of Preventive Medicine. 2002; 23(4):260-268. [PubMed: 12406480] 
Coker AL, Smith PH, McKeown RE, King MJ. Frequency and correlates of intimate partner violence by type: Physical, sexual, and psychological battering. American Journal of Public Health. 2000; 90(4):553-559. [PubMed: 10754969]

Cox JL, Chapman G, Murray D, Jones P. Validation of the Edinburgh Postnatal Depression Scale in non-postnatal women. Journal of Affective Disorders. 1996; 39:185-189. [PubMed: 8856422]

Creswell, J.; Plano-Clark, V. Designing and conducting mixed methods research. Thousand Oaks, CA: Sage; 2007.

Decker M, Martin S, Moracco KE. Homicide risk factors among pregnant women abused by their partners who leaves the perpetrator and who stays? Violence against Women. 2004; 10(5):498513.

Dunn LL, Oaths KS. Prenatal predictors of intimate partner violence. Journal of Obstetrics, Gynecologic and Neonatal Nursing. 2004; 33(1):54-63.

Fried LE, Cabral H, Amaro H, Aschengrau A. Lifetime and during pregnancy experience of violence and the risk of low birth weight and preterm birth. Journal of Midwifery and Women's Health. 2008; 53(6):522-528.

Gaynes BN, Gavin N, Meltzer-Brody S, Lohr KN, Swinson T, Gartlehner G, Miller WC. Perinatal depression: Prevalence, screening accuracy, and screening outcomes. Agency for Healthcare Research and Quality. 2005; 119:1-8.

Gilligan, C.; Rogers, A.; Tolman, D. Women, girls and psychotherapy: Reframing resistance. New York, NY: Haworth; 1991.

Glaser, BG. Theoretical sensitivity: Advances in the methodology of grounded theory. Mill Valley, CA: Sociology Press; 1978.

Golding JM. Intimate partner violence as a risk factor for mental disorders: A meta-analysis. Journal of Family Violence. 1999; 14(2):99-132.

Gross KH, Wells CS, Radigan-Garcia A, Dietz PM. Correlates of self-reports of being very depressed in the months after delivery: Results from the Pregnancy Risk Assessment Monitoring System. Maternal \& Child Health Journal. 2002; 6(4):247-253. [PubMed: 12512766]

Horon IL, Cheng D. Enhanced surveillance for pregnancy associated mortality in Maryland, 19931998. Journal of the American Medical Association. 2001; 285:1455-1459. [PubMed: 11255421]

Jasinski JL, Kaufman K. Pregnancy, stress and wife assaults: Ethnic differences in prevalence, severity and onset in a national sample. Violence and Victims. 2001; 16(3):1-14.

Jones S, Bogat A, Davidson W, Eye AV, Levendosky A. Family support and mental health in pregnant women experiencing interpersonal partner violence: An analysis of ethnic differences. American Journal of Community Psychology. 2005; 36(1/2):97-108. [PubMed: 16134047]

Larson, R.; Richards, MH. Divergent realities. New York, NY: Basic; 1994.

Leahy-Warren P, McCarthy G, Corcoran P. First-time mothers: Social support, maternal parental selfefficacy and post-natal depression. Journal of Clinical Nursing. 2011; 20

Levendosky AA, Bogat GA, Theran SA, Trotter J, Von Eye AV, Davidson WS. The social networks of women experiencing domestic violence. American Journal of Community Psychology. 2004; 34:95-109. [PubMed: 15495797]

Lyons-Ruth, K.; Wolfe, R.; Lyubchik, A.; Steingard, R. Depressive symptoms in parents of children under age 3: Sociodemographic predictors, current correlates, and associated parenting behaviors. In: Halfon, N.; Taaffe McLearn, K., editors. Child rearing in America: Challenges facing parents with young children. New York, NY: Cambridge University Press; 2002. p. 217-259.

Martin S, Li Y, Casanueva C, Harris-Britt A, Kupper L, Cloutier S. Intimate partner violence and women's depression before and during pregnancy. Violence against Women. 2006; 12(3):221239. [PubMed: 16456149]

Martin S, Mackie L, Kupper L, Buescher PA, Moracco KE. Physical abuse of women before, during, and after pregnancy. Journal of the American Medical Association. 2001; 285(12):1581-1584. [PubMed: 11268265]

Matthey S, Henshaw C, Elliott S, Barnett B. Variability in use of cut-off scores and formats on the Edinburgh Postnatal Depression Scale-implications for clinical and research practice. Archives of Women's Mental Health. 2006; 9:309-315. 
McClellan AC, Killeen MR. Attachment theory and violence toward women by male intimate partners. Clinical Scholarship. 2000; 32(4):353-360.

McKee MD, Cunningham M, Jankowski KR, Zayas L. Health related functional status in pregnancy: Relationships to depression and social support in a multiethnic population. Obstetrics and Gynecology. 2001; 97:988-993. [PubMed: 11384708]

Noel NL, Yam M. Domestic violence: The pregnant battered woman. Women's Health. 1992; 27(4): 871-884.

Oakley A, Rajan L, Grant A. Social support and pregnancy outcome. British Journal of Obstetrics and Gynecology. 1990; 97:155-162.

Parker B, McFarlane J. Identifying and helping pregnant battered women. Maternal-Child Health. 1991; 16:161-164.

Parker B, McFarlane J, Soeken K. Abuse during pregnancy: Effects on maternal complications and birth weight in adult and teenage women. Obstetrics and Gynecology. 1994; 84(3):323-328. [PubMed: 8058224]

Parsons LH, Harper MA. Violent maternal deaths in North Carolina. Obstetrics and Gynecology. 1999; 94:990-993. [PubMed: 10576188]

Rodriguez M, Valentine J, Ahmed S, Eisenman D, Sumner L, Heilemann M, Liu H. Intimate partner violence and maternal depression during the perinatal period: A longitudinal investigation of Latinas. Violence against Women. 2010; 16:543-559. [PubMed: 20388930]

Saltzman LE, Fanslow JL, McMahon PM, Shelley GA. Intimate partner violence surveillance: Uniform definitions and recommended data elements. Version 1.0. 1999Atlanta, GACenters for Disease Control and Prevention, National Center for Injury Prevention and Control This is the reference and the definition is provided by $\mathrm{CDC}$.

Saltzman LE, Johnson CH, Gilbert BC, Goodwin MM. Physical abuse around the time of pregnancy: An examination of prevalence and risk factors in 16 states. Maternal and Child Health Journal. 2003; 7:31-43. [PubMed: 12710798]

Sharps PW, Laughon K, Giangrande S. Intimate partner violence and the child bearing year: Maternal and infant health consequences. Trauma, Violence, \& Abuse. 2007; 8(2):105-116.

Soenens B, Vansteenkiste M, Luyckx K, Goosens L. Parenting and adolescent problem behavior: An integrated model with adolescent self-disclosure and perceived parental knowledge as intervening variables. Developmental Psychology. 2006; 42(2):305-318. [PubMed: 16569169]

Stampfel C, Chapman DA, Alvarez AE. Intimate partner violence and posttraumatic stress disorder among high-risk women: Does pregnancy matter. Violence against Women. 2010; 16(4):426-443. [PubMed: 20224113]

Strauss, A.; Corbin, JM. Basics of qualitative research: Grounded theory procedures and techniques. 2nd ed.. Thousand Oaks, CA: Sage; 1998.

Taillieu TL, Brownridge DA. Violence against pregnant women: Prevalence, patterns, risk factors, theories, and directions for future research. Aggression and Violent Behavior. 2010; 15(1):14-35.

Tjaden, P.; Thoennes, N. Extent, nature, and consequences of intimate partner violence: Findings from the National Violence Against Women Survey. Washington, DC: National Institute of Justice; 2000.

Webster J, Chandler J, Battistutta D. Pregnancy outcomes and health care use: Effects of abuse. American Journal of Obstetric Gynecology. 1996; 174(2):760-767.

Wilen JM, Mounds KO. Women with depression: "You can't tell by looking”. Maternal and Child Health Journal. 2006; 10:S183-S186. [PubMed: 16752092]

Yost NP, Bloom SL, McIntire DD, Leveno KJ. A prospective observational study of domestic violence during pregnancy. Obstetrics \& Gynecology. 2005; 106(1):61-65. [PubMed: 15994618] 
TABLE 1

\section{Themes from 37 Codes}

\begin{tabular}{|c|c|}
\hline Themes & Codes \\
\hline \multirow[t]{2}{*}{ 1. Abuser's reaction to abuse } & 1. Abuser's reaction to action by participant \\
\hline & 2. Abuser's reaction to abusive situation \\
\hline 2. Behavioral reaction to abuse & 30. Reaction to abuse \\
\hline \multirow[t]{2}{*}{ 3. Broken spirit } & 16. Feelings associated with abuse or abuser \\
\hline & 30. Reaction to abuse \\
\hline \multirow[t]{3}{*}{ 4. Choices or decision making } & 5. Barriers to resources for leaving partner \\
\hline & 8. Choices or decision making process \\
\hline & 26. Motivation for changing situation \\
\hline \multirow[t]{2}{*}{ 5. Desirability of relationship } & 15. Feelings about relationship with abuser \\
\hline & 36. Views of marriage \\
\hline 6. Family involvement & 13. Family context of abuse \\
\hline \multirow[t]{10}{*}{ 7. Patterns of abuse } & 4. Assessment of severity of abuse \\
\hline & 7. Characteristics of abuser according to participant \\
\hline & 10. Dealing with problems, conflict, and anger \\
\hline & 11. Denies abuse: current partner \\
\hline & 12. Descriptions of abuse \\
\hline & 17. Fussing \\
\hline & 19. Her use of violence \\
\hline & 27. New relationships \\
\hline & 32. Sexual activity: postnatal \\
\hline & 37. When abuse started \\
\hline \multirow[t]{5}{*}{ 8. Perception of self or role } & 6. Changing perceptions of self or role \\
\hline & 13. Family context of abuse \\
\hline & 18. Future \\
\hline & 31. Reaction to and feelings about pregnancy \\
\hline & 33. Stressors \\
\hline 9. Study questions & 34. Study questions \\
\hline \multirow[t]{3}{*}{ 10. Support seeking } & 3. Asked about DV/IPV \\
\hline & 9. Consequences of taking action \\
\hline & 35. Support seeking or agency involvement \\
\hline \multirow[t]{9}{*}{ 11. What we bring to the table (history) } & 10. Dealing with problems, conflict, and anger \\
\hline & 14. Family history \\
\hline & 20. History of IPV \\
\hline & 21. History of abuse or trauma \\
\hline & 22. History of alcohol or drug use \\
\hline & 23. Living situation \\
\hline & 25. Mental health issues \\
\hline & 28. Positive events in participants' lives \\
\hline & 29. Quality of family relationship \\
\hline
\end{tabular}

Issues Ment Health Nurs. Author manuscript; available in PMC 2015 December 17. 


\begin{tabular}{ll}
\hline Themes & Codes \\
\hline & 33. Stressors \\
12. Child abuse/loss of custody & 24. Loss of custody \\
\hline
\end{tabular}


TABLE 2

Demographic Characteristics at Baseline

\begin{tabular}{llcc}
\hline & Category & $\begin{array}{c}\text { Rural } \\
(\boldsymbol{n}=\mathbf{2 1})\end{array}$ & $\begin{array}{c}\text { Urban } \\
(\boldsymbol{n}=\mathbf{9})\end{array}$ \\
\hline Age & & $\mathrm{X}=24.23$ & $\mathrm{X}=23.78$ \\
Education & & & \\
& No high school diploma & 3 & 6 \\
& High school diploma & 8 & 1 \\
& Some college or trade school & 7 & 2 \\
& Trade school/CC graduate & 3 & 0 \\
Race & & & \\
& African American & 4 & 9 \\
& European American & 15 & 0 \\
& American Indian & 2 & 0 \\
\hline
\end{tabular}

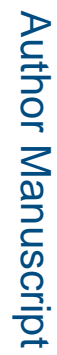

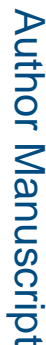

American Indian 
TABLE 3

Baseline and Six Month Depressive Scores of DOVE Participants in Regard to their Relationship with their Mothers

\begin{tabular}{lcc}
\hline & \multicolumn{2}{c}{ Depression } \\
\cline { 2 - 3 } Relationship with Mother & Baseline & 6 Months \\
\hline Positive Relationship $(n=11)$ & & \\
Mean & 13 & 5.18 \\
Range & $4-19$ & $2-14$ \\
Negative Relationship $(n=19)$ & & \\
Mean & 14.78 & 10.42 \\
Range & $9-24$ & $0-28$ \\
\hline
\end{tabular}


TABLE 4

Relationship with Mothers and Six Month Scores for Depressive Symptoms Type of Relationship with Mothers

\begin{tabular}{lcccc}
\hline & Positive $(\boldsymbol{n}=\mathbf{1 1})$ & Negative $(\boldsymbol{n}=\mathbf{1 9})$ & $\boldsymbol{t}$ & $\mathbf{d f}$ \\
\hline Depressive symptoms & 5.18 & 10.42 & $2.15^{*}$ & 28 \\
& $(4.24)$ & $(7.37)$ & & \\
\hline
\end{tabular}

${ }^{*} p<.05$.

Note: Standard Deviations appear in parentheses below Mean. 
TABLE 5

Six Month Depressive Symptom Scores of DOVE Participants with Negative Relationship with their Mothers

\begin{tabular}{|c|c|c|}
\hline $\begin{array}{l}\text { Depressive } \\
\text { Symptoms } \\
\text { Scores }\end{array}$ & $\begin{array}{c}\text { Negative } \\
\text { Relationship with } \\
\text { Mother, Positive } \\
\text { with Another Adult } \\
(n=12)\end{array}$ & $\begin{array}{c}\text { Negative } \\
\text { Relationship with } \\
\text { Mothers, no Other } \\
\text { Support }(n=7)\end{array}$ \\
\hline Mean & 6 & 18 \\
\hline Range & $0-11$ & $13-28$ \\
\hline
\end{tabular}


TABLE 6

Negative Relationship with Mothers and Six Month Scores for Depressive Symptoms

\begin{tabular}{|c|c|c|c|c|}
\hline \multicolumn{5}{|c|}{ Negative Relationship with Mothers and Positive Relationship with Another Adult } \\
\hline & Neg w/Mother $(n=12)$ & Pos w/Another Adult $(n=7)$ & $t$ & df \\
\hline Depressive Symptoms & $\begin{array}{c}18 \\
(5.23)\end{array}$ & $\begin{array}{l}5.85 \\
(4)\end{array}$ & $5.71^{* * *}$ & 17 \\
\hline
\end{tabular}

$* * *$

$p<.0001$.

Note: Standard Deviations appear in parentheses below Mean. 